\title{
"IN GERMANY BEFORE THE WAR", DE RANDY NEWMAN: UMA PROPOSTA DE TRADUÇÃO DA CANÇÃO
}

\author{
Caetano Galindo 1 \\ 1Universidade Federal do Paraná, Curitiba, Paraná, Brasil \\ Paulo Henriques Britto르 \\ 2Ponficia Universidade Católica do Rio de Janeiro, Rio de Janeiro, \\ Rio de Janeiro, Brasil
}

Resumo: Este texto oferece uma detalhada análise da articulação dos níveis formal e semântico da canção de Newman na tentativa de localizar seus mecanismos expressivos como texto poético, primeiro, e como canção. A partir disso, propomos uma tradução da canção que pretende atingir os mesmos objetivos, mantendo-se legível e cantável nos mesmos termos estabelecidos pelo original.

Palavras-Chave: Análise do Texto Musical; Canção Americana; Versão para Canto

\section{"IN GERMANY BEFORE THE WAR", DE RANDY NEWMAN: UMA PROPOSTA DE TRADUÇÃO DA CANÇÃO}

\begin{abstract}
This article presents a detailed analysis of the interaction between the formal and semantic levels of a song by Randy Newman, attempting to pinpoint its expressive mechanisms both as poetic text and as song. On this basis, we offer a Brazilian Portuguese translation of the song that tries to achieve the same effects, so that it can be read and sung on the same terms as the original.
\end{abstract}

Keywords: Analysis of Musical Text; U.S.A Songs; Song Translation 
Randy Newman (1943 - ) vem construindo, desde os anos 60, uma brilhante carreira de cancionista, tornado-se um dos maiores nomes da canção americana no século XX. Percorrendo muitas vezes uma indefinível linha entre ironia e sátira (escrevendo in character, numa voz lírica distinta da sua), Newman estabeleceu para si uma posição absolutamente ímpar.

Seu disco Little Criminals (1977) incluía a faixa "In Germany Before the War", uma das ocasiões em que ele mais buscou levar a forma da canção popular norte-americana aos limites da narrativa dramática e da flexibilidade estrutural do Lied europeu. A canção foi regravada por ele em The Randy Newman Songbook, vol. 1(2008), álbum acompanhado por um livro com as letras, melodias e harmonias das 15 canções (mais 3 faixas instrumentais) registradas.

Nossa análise faz referência às duas versões. A letra utilizada é a apresentada no Songbook, embora possamos recorrer a quebras e enjambements sugeridos pela prosódia das gravações. Nosso objetivo é pensar na tradução não apenas de um poema, e sim de uma canção, que é como o texto de fato funciona.

\section{IN GERMANY BEFORE THE WAR}

\section{Randy Newman}

In Germany before the war

There was a man who owned a store

In nineteen hundred thirty-four

In Dusseldorf

And every night at five-o-nine

He'd cross the park down to the Rhine

And he'd sit there by the shore

I'm looking at the river

But I'm thinking of the sea 
Thinking of the sea

I'm looking at the river

But I'm thinking of the sea

A little girl has lost her way

With hair of gold and eyes of gray

Reflected in his glasses

As he watches her

A little girl has lost her way

With hair of gold and eyes of gray

I'm looking at the river

But I'm thinking of the sea

Thinking of the sea

We lie beneath the autumn sky

My little golden girl and I

And she lies very still

A primeira coisa a se comentar é o título aparentemente redundante. Mas o contato com a obra de Newman não nos autoriza a desconsiderar esse tipo de procedimento. Basta pensar em "Texas Girl at the Funeral of Her Father", onde o título dá a chave para todo o sentido final da canção. O título parece sublinhar informações que seriam dedutíveis depois.

Vem também à tona uma segunda manobra, especialmente antes de se ouvir a canção. O título pode nos fazer esperar uma canção de espectro mais amplo, sobre um contexto histórico (como "Sigmund Freud's Impersonation of Albert Einstein in America") ou questões mais abrangentes (como "Political Science" ou "The Great Nations of Europe").

Esse jogo entre informação específica e "suspense" continua existindo em toda a primeira estrofe: 
In Germany, before the war

There was a man, who owned a store

In nineteen hundred thirty-four

In Düsseldorf

Destaquemos o contraste entre detalhe e generalidade. A primeira informação ("na Alemanha") parece fria e precisa, porém será qualificada no último verso ("em Düsseldorf”). O mesmo acontece com "antes da guerra", ainda mais detalhado no terceiro verso.

Isso gera uma relação de simetria/dependência entre tudo que está nos versos 1, 3 e 4, ressaltando ainda mais o aspecto estranho da informação presente no segundo. Em meio a tanta objetividade, existe um homem que "owned a store". Não se sabe o que ele faz, nem quem ele é.

Outro dado é que Düsseldorf nos anos 30 insinua a presença de $M$, filme que Fritz Lang lança em 1931 sobre acontecimentos que ocorreram na cidade alguns anos antes. Isso empresta àquele man tons algo ominosos.

A segunda estrofe prossegue oscilando entre o preciso e o indeterminado:

And every night, at five-o-nine

He'd cross the park down to the Rhine

And he'd sit there by the shore

O horário é dado em detalhes (mas seriam cinco e nove antes de o sol nascer ou depois de se pôr?). O parque não é nomeado, embora o rio seja. E o texto se interrompe com o uso algo desviante da palavra shore para se referir à margem do Reno.

Em termos métricos, a estrofação que propomos gera uma primeira estrofe de quatro versos predominantemente jâmbicos, com três tetrâmetros, encerrando-se por um dímetro, verso quebrado que pode ser lido como o princípio de toda uma série de suspensões na canção. 
Quanto à rima, novamente o quarto verso se destaca, por rimar de maneira incompleta, embora mantenha a qualidade vocálica constante entre todas as rimas.

$\mathrm{Na}$ estrofe seguinte há um contraste, nos dois primeiros versos, entre o padrão métrico mantido (dois tetrâmetros jâmbicos) e uma rima diferente que separa este dístico da estrutura até agora conservada. O terceiro verso gera outro tipo de contraste, ao retomar a rima em -ore, mas criar um terceiro modelo métrico, baseado num trímetro jâmbico se considerarmos menos a letra escrita do que sua vocalização.

A grande suspensão é a ausência do verso que fecharia o quarteto, ainda mais marcada pelo acompanhamento obbligato do piano, que continua escandindo uma frase omitida.

Até aqui, muito do que se disse do poema ficou marcado pela tensão entre dito e não dito. Mais produtiva ainda associar essa semântica a discretas manipulações formais (quebras de expectativa) que fazem muito por sublinhar ausências.

A essas estrofes segue-se o refrão.

I'm looking at the river

But I'm thinking of the sea

Thinking of the sea

I'm looking at the river

But I'm thinking of the sea

A semântica, de novo, é inapreensível. Quem é o eu que subitamente toma posse do poema? Uma voz narradora, ou o homem?

E há o problema de se determinar o sentido. Uma interpretação direta é possível, mas mesmo ela nos levaria a um sentido quase alegórico. Olhar para o rio e pensar no mar seria conceber uma saída?

Ou simplesmente deixar o olhar se perder? 
Outras leituras surgem, em que o contexto alemão faria pensar na ascensão do nacional-socialismo: o mar, aqui prefigurado pelo rio local das primeiras manifestações nazistas.

Mas a "simplicidade" de um refrão que se constrói sobre a repetição de uma sentença clara (conotativamente ambígua) é desmentida pelo mecanismo de repetição e frustração de expectativa estabelecido desde o início. Depois da primeira apresentação da sentença, temos não uma nova ideia, nem mesmo uma repetição, mas apenas o eco de sua metade final, thinking of the sea, uma vez em voz e piano e, no que seria o quarto verso, com silêncio vocal sublinhado pela conclusão do arco melódico no obbligato do piano. $\mathrm{O}$ mecanismo passa a ser do tipo $\mathrm{AB} / \mathrm{B} / \ldots$

A segunda iteração, a pretensa repetição do refrão, demole ainda mais a esperada simetria. Primeiro porque, apesar de as palavras inicialmente aparecerem repetidas, a frase musical sofre uma alteração brusca, com um salto de uma terça menor a partir da sexta sílaba. Repetição e novidade simultâneas:

\section{Figura 1}

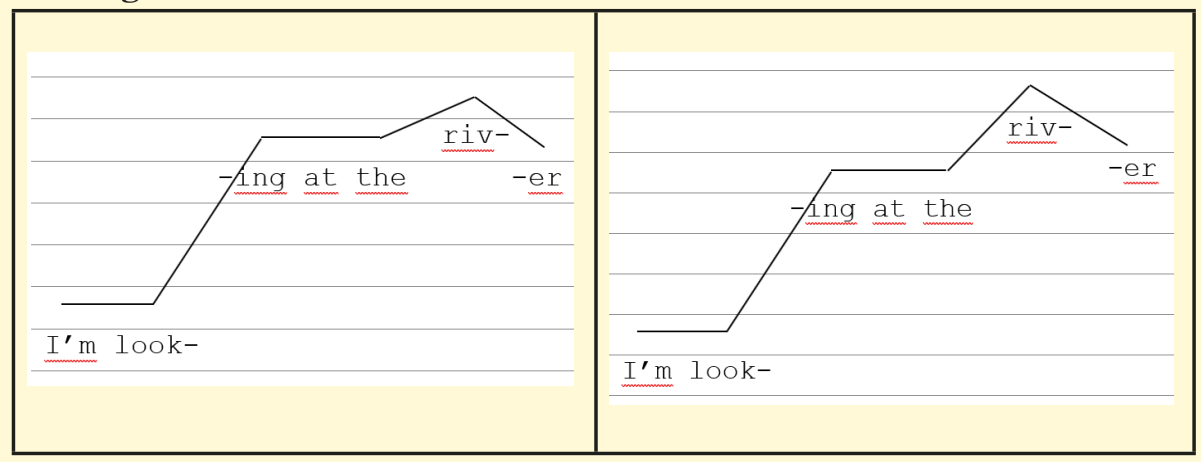

Fonte: Os autores.

Depois disso, em vez do reaparecimento da estrutura, temos outra vez a frustração de um padrão, pois não existe o eco de thinking of the sea. Mais ainda, retorna o obbligato do piano sublinhando a omissão de palavras. 
A canção está apresentada. Os mecanismos foram desenvolvidos. A conclusão de um movimento é marcada pela primeira aparição do "refrão", e pela reapresentação da introdução instrumental que precedia o primeiro verso.

A estrofe seguinte -
A little girl has lost her way
With hair of gold and eyes of gray
Reflected in his glasses
As he watches her

- parece reforçar essa cisão ao trocar de personagem, e talvez de cena. Estamos novamente no domínio do preciso/impreciso, com uma descrição de detalhes da aparência de uma menininha.

A estrofe instaura também um novo padrão de rimas em $a y$, que será desmentido pela quase-rima em er no quarto verso, curiosa evocação consonantal das rimas em or do início.

Novamente temos mecanismos de supressão e realce de expectativas, porém, pois os dois primeiros versos repetem o molde do tetrâmetro esperado, mas o terceiro e o quarto, graças à enunciação que os faz soar como uma frase sem "pausas", parecem fundir numa única unidade, de doze sílabas e escansão menos regular, o que poderiam ser dois versos. A instabilidade atinge o grau máximo, e isso se reflete em ao menos duas outras características neste momento.

A primeira é a síntese que funde a menina e seu observador (aquele homem?) jogando a perspectiva para o reflexo nos óculos dele, acentuada por um belíssimo efeito de repetição (glasses as he), com a execução de Newman eliminando a consoante de he, gerando um efeito de eco, gaguejamento que iconiza a menina "repetida" nas lentes.

Esse efeito vocálico demanda o enjambement que (des)caracteriza a quadra e se soma à alteração da parte instrumental: se até aqui às cordas se somavam apenas, e eventualmente, trompa e trompete, agora surgem (e apenas neste momento) flautas e o que parecem ser discretos sons de marimba. 
Mas o mais marcante efeito de desestabilização é o acompanhamento ao piano deixar de ser univocamente menor, incluindo na parte superior a terça maior do acorde de fá, por exemplo, que acompanha o primeiro verso.

Ao descentrar a mais clássica das distinções do sistema diatônico, entre tonalidades maiores e menores, o piano introduz um índice de perturbação persistente que o vocal de Newman só aumenta. A partitura incluída no Songbook prevê que o cantor altere também a melodia para esse padrão maior, numa manobra schubertiana que sublinha a melancolia abandonando o campo menor.

Mas o canto de Newman, acostumado à ambiguidade das terças no blues e no jazz, mantém certa indefinição, gerando efeito ainda mais perturbador, conquanto discreto.

Essa nova estrofe, que pode parecer abandonar o padrão de quatro versos, devendo ser sucedida por nova estrofe modelada de maneira similar, na verdade abre espaço para uma repetição exata de seus dois primeiros versos - apenas dos dois primeiros.

É como se o texto dissesse que algo mais poderia ser dito, mas preferissese entregar ao silêncio, mais gritante se o piano continua "cantando" a melodia sem letra.

A segunda aparição do "refrão" parece agora vir mais cedo, pois a estrutura das estrofes foi esgarçada, criando agora ainda menos respostas, e mais ambiguidade.

Primeiro, porque ele repete a mesma sentença, ainda mais estranha ("Ele" não estaria olhando para a menina? É "ela" o rio? E o que seria o mar?). Segundo, porque o mecanismo de deleção continua operando, especialmente na versão de 2008, onde $\mathrm{Ne}$ wman não realiza nenhum dos ecos do sintagma thinking of the sea da segunda estrofe.

Sendo a voz do cantor progressivamente substituída pelo acompanhamento, que assim ganha ares de "protagonismo", o silêncio fica cada vez maior.

Depois de mais uma apresentação da introdução, o vocal retorna. 
We lie beneath the autumn sky

My little golden girl and I

And she lies very still

De novo dois tetrâmetros jâmbicos e um paradigma de rimas que aparece pela primeira vez. Mas o terceiro verso é diferente. Seis sílabas, três pés, dos quais o segundo não é claramente jâmbico, e a única palavra de todo o poema que não rima.

Não há um quarto verso, novamente escandido apenas pelo piano, nem uma segunda estrofe, novamente delineada apenas pelo acompanhamento, agora dissonantíssimo.

Se o poema começou falando de um ele e uma ela, com estranhas incursões por um $e u$, agora o $e u$ toma posse do discurso e da menina, não apenas graças ao pronome de primeira pessoa plural, mas por chamá-la de minha. No mesmo movimento dessa dança de pronomes, as três cenas são fundidas numa linha que vai da descrição prosaica daquele homem ao momento horripilante em que a menina é vista, e à cena macabra em que ela se torna posse dessa voz e lies very still.

$\mathrm{O}$ que dizer do fato de que aquela ausência do quarto verso, o paradigma de rimas, e todo o contexto narrativo, parecem indicar a presença/ausência de to die?

Não seria um recurso totalmente inédito para Newman, que anos antes encerrara "Texas Girl at the Funeral of her Father" com manobra parecida: métrica e rima nos fariam supor a palavra again, que a moça não ousa pronunciar porque a morte do pai interrompeu essa possibilidade.

$*$

É essa a análise formal/semântica em que fundamentamos uma proposta de tradução: 


\begin{tabular}{|c|c|}
\hline $\begin{array}{l}\text { IN GERMANY BEFORE THE } \\
\text { WAR }\end{array}$ & $\begin{array}{l}\text { NA ALEMANHA, ANTES DA } \\
\text { GUERRA }\end{array}$ \\
\hline $\begin{array}{l}\text { In Germany before the war } \\
\text { There was a man who owned a store } \\
\text { In nineteen hundred thirty-four } \\
\text { In Düsseldorf }\end{array}$ & $\begin{array}{l}\text { Em paz ainda, em trinta e três, } \\
\text { Em Düsseldorf, às cinco e dez, } \\
\text { Ele não entra nos cafés } \\
\text { E vai sereno }\end{array}$ \\
\hline $\begin{array}{l}\text { And every night at five-o-nine } \\
\text { He'd cross the park down to the Rhine } \\
\text { And he'd sit there by the shore }\end{array}$ & $\begin{array}{l}\text { Já encerrado o expediente } \\
\text { Caminha até o parque em frente } \\
\text { E olha para o Reno }\end{array}$ \\
\hline $\begin{array}{l}\text { I'm looking at the river } \\
\text { But I'm thinking of the sea } \\
\text { Thinking of the sea } \\
\text { I'm looking at the river } \\
\text { But I'm thinking of the sea }\end{array}$ & $\begin{array}{l}\text { Eu olho para o rio } \\
\text { Mas eu penso é no mar } \\
\text { Eu penso é no mar } \\
\text { Eu olho para o rio } \\
\text { Mas eu penso é no mar }\end{array}$ \\
\hline $\begin{array}{l}\text { A little girl has lost her way } \\
\text { With hair of gold and eyes of gray } \\
\text { Reflected in his glasses } \\
\text { As he watches her } \\
\text { A little girl has lost her way } \\
\text { With hair of gold and eyes of gray }\end{array}$ & $\begin{array}{l}\text { Menina loura, se perdeu, } \\
\text { Olhos azuis, da cor do céu, } \\
\text { Reflete-se nas lentes } \\
\text { Dele, bem atentas } \\
\text { Menina loura, se perdeu } \\
\text { Olhos azuis, da cor do céu }\end{array}$ \\
\hline $\begin{array}{l}\text { I'm looking at the river } \\
\text { But I'm thinking of the sea } \\
\text { Thinking of the sea }\end{array}$ & $\begin{array}{l}\text { Eu olho para o rio } \\
\text { Mas eu penso é no mar } \\
\text { Eu penso é no mar }\end{array}$ \\
\hline $\begin{array}{l}\text { We lie beneath the autumn sky } \\
\text { My little golden girl and I } \\
\text { And she lies very still }\end{array}$ & $\begin{array}{l}\text { Eu e a menina no gramado } \\
\text { Assim imóvel a meu lado } \\
\text { Ela me conforta }\end{array}$ \\
\hline
\end{tabular}

Cad. Trad., Florianópolis, v. 41, $\mathrm{n}^{0}$ 1, p. 100-124, jan-abr, 2021. 
A intenção foi recuperar tanto quanto possível os elementos formais do original, preservando o sentido. Comecemos com o esquema de rimas. No original, temos aaaa' bba CDDCD EexxE CDDD $f f x$, onde $x$ acusa a inexistência de rima; maiúsculas indicam rimas idênticas - uma palavra rimando com si própria; o símbolo ' indica rima incompleta. Assim, $a$ representa as rimas completas ar, store, four; $a$ ' representa Düsseldorf, rimando incompletamente com os versos anteriores, pois não há /f/ final em $a$; $C$ refere-se a river, que rima com si própria. Analogamente, representamos o esquema rímico da tradução como $a a a b$ ccb DEEDE Ffcc' $F$ DEEE ggx. (Consideramos completas as rimas entre três /e/ e dez /e/, seguindo a tradição, mas não entre lentes e atentas.) A tradução não reproduz exatamente a estrutura original, mas mantém uma característica importante: só o verso final não rima, porém evoca uma palavra ausente ("morta"), efeito obtido em inglês com a rima em $f$ /ai/. Outra diferença é que, enquanto no original todas as rimas são masculinas, na tradução apenas $a$ e $d$ são masculinas; todas as outras terminam com uma átona, obrigando o cantor a acrescentar uma nota ao final desses versos.

Vejamos a estrutura métrica do original e da versão. Nas tabelas abaixo, sílabas átonas são representadas por -; acentos primários, por /; acentos secundários, por $\backslash$; pausas, por $\|$. O símbolo [-] indica átona ao final de verso ou hemistíquio assimilada à vogal inicial da sílaba átona do verso ou hemistíquio seguinte (sinalefa). 


\begin{tabular}{|c|c|c|}
\hline & IN GERMANY BEFORE THE WAR & \\
\hline $\mathbf{A}$ & $\begin{array}{l}\text { In Germany before the war } \\
\text { There was a man who owned a store } \\
\text { In nineteen hundred thirty-four } \\
\text { In Düsseldorf }\end{array}$ & $\begin{array}{l}-1--||-1-1 \mid \\
--1||-1-1 \mid \\
-/ 1 /-1-1 \mid \\
-1-1 \mid\end{array}$ \\
\hline B & $\begin{array}{l}\text { And every night at five-o-nine } \\
\text { He'd cross the park down to the Rhine } \\
\text { And he'd sit there by the shore }\end{array}$ & $\begin{array}{l}-1-1||-1-1 \mid \\
-1-1|| 1--1|| \\
--1-|| 1-1 \mid\end{array}$ \\
\hline $\mathbf{C}$ & $\begin{array}{l}\text { I'm looking at the river } \\
\text { But I'm thinking of the sea } \\
\text { Thinking of the sea } \\
\text { Thinking of the sea } \\
\text { I'm looking at the river } \\
\text { But I'm thinking of the sea }\end{array}$ & $\begin{array}{l}-1--1-|| \\
--1--1|| \\
|--1| \mid \\
|--1| \mid \\
-1--1-|| \\
--1--1 \mid\end{array}$ \\
\hline D & $\begin{array}{l}\text { A little girl has lost her way } \\
\text { With hair of gold and eyes of gray } \\
\text { Reflected in his glasses } \\
\text { As he watches her } \\
\text { A little girl has lost her way } \\
\text { With hair of gold and eyes of gray }\end{array}$ & $\begin{array}{l}-1-1||-1-1 \mid \\
-1-1||-1-1 \mid \\
-1--1-|| \\
--1--|| \\
-1-1||-1-1 \mid \\
-1-1||-1-1 \mid\end{array}$ \\
\hline $\mathbf{E}$ & $\begin{array}{l}\text { I'm looking at the river } \\
\text { But I'm thinking of the sea } \\
\text { Thinking of the sea }\end{array}$ & $\begin{array}{l}-1--1-|| \\
--1--1|| \\
|---1|\end{array}$ \\
\hline $\mathbf{F}$ & $\begin{array}{l}\text { We lie beneath the autumn sky } \\
\text { My little golden girl and I } \\
\text { And she lies very still }\end{array}$ & $\begin{array}{l}-1-1||-1-1 \mid \\
-1-1-1||-1|| \\
--1 /-1||\end{array}$ \\
\hline
\end{tabular}




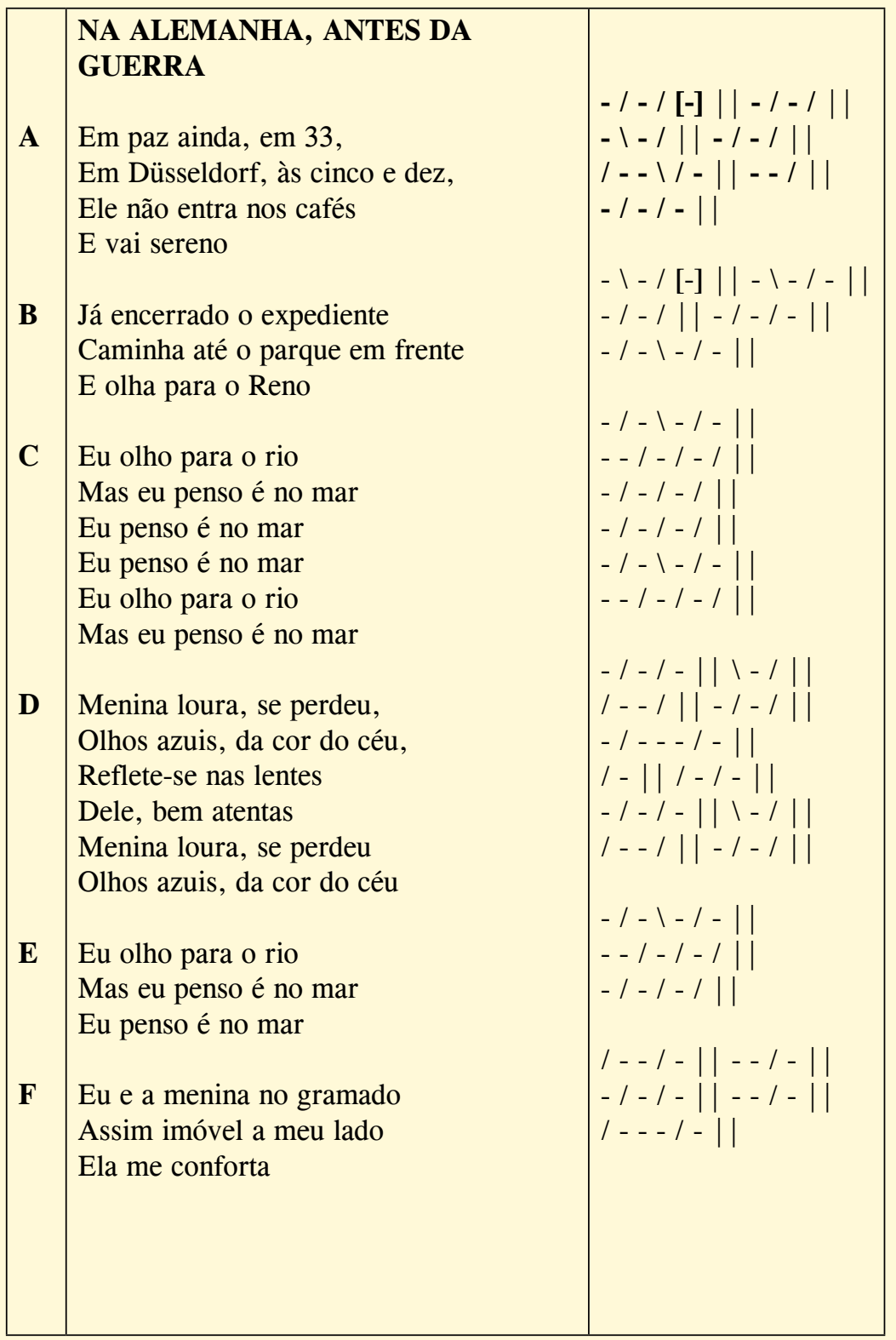


Vejamos lado a lado as escansões.

\begin{tabular}{|c|c|c|}
\hline & ORIGINAL & TRADUÇÃO \\
\hline $\mathbf{A}$ & $\begin{array}{l}-1--||-1-1 \mid \\
--1||-/-/|| \\
-/ \backslash /-1-1 \mid \\
-/-1||\end{array}$ & $\begin{array}{l}-1-/[-]||-/-1|| \\
-1-/||-1-1|| \\
1--1 /-||--1|| \\
-1-1-||\end{array}$ \\
\hline B & $\begin{array}{l}-1-1||-1-1|| \\
-1-1|| 1--1|| \\
--1-|| 1-1 \mid\end{array}$ & $\begin{array}{l}-1-/[-]||-1-1-|| \\
-1-1||-1-1-|| \\
-1-1-1-||\end{array}$ \\
\hline $\mathbf{C}$ & $\begin{array}{l}-1--1-1 \mid \\
--1--1|| \\
|--1| \mid \\
|--1| \\
-1--1 \mid \\
--1--1 \mid\end{array}$ & $\begin{array}{l}-1-1-1-1 \mid \\
--1-1-1|| \\
-1-1-1|| \\
-1-1-1 \mid \\
-1-1-1-1 \mid \\
--1-1-1 \mid\end{array}$ \\
\hline D & $\begin{array}{l}-1-1||-1-1|| \\
-1-1||-1-1 \mid \\
-1--1-1 \mid \\
--1--|| \\
-1-1||-1-1|| \\
-1-1||-1-1||\end{array}$ & $\begin{array}{l}-1-1-|||-1| \mid \\
1--1||-1-1 \mid \\
-1--1-|| \\
1-|| 1-1-|| \\
-1-1-|| 1-1|| \\
1--1||-1-1 \mid\end{array}$ \\
\hline $\mathbf{E}$ & $\begin{array}{l}-1--1-|| \\
--1--1|| \\
|---1|\end{array}$ & $\begin{array}{l}-1-1-1-|| \\
--1-1-1|| \\
-1-1-1||\end{array}$ \\
\hline $\mathbf{F}$ & $\begin{array}{l}-1-1||-1-1 \mid 1 \\
-1-1-1||-1|| \\
--1 /-1||\end{array}$ & $\begin{array}{l}-1-1-|1--1-| \mid \\
-1-1-1-1-|| \\
-1-|| 1-1-1 \mid\end{array}$ \\
\hline
\end{tabular}


As estrofes A, B, D e F - que correspondem à melodia principal - seguem, no original, o padrão - / - / || - / - / ||, um octossílabo com cesura após a quarta sílaba, ou então um tetrâmetro jâmbico com cesura após o segundo pé. Em A, o quarto verso contém apenas um pé; B e F têm apenas três versos. Nas duas ocorrências do estribilho $-\mathrm{C}$ e $\mathrm{E}-\mathrm{o}$ número de sílabas varia entre 5 e 7, mas o número de sílabas acentuadas é sempre 2; aqui não temos cesuras.

Passemos para a segunda coluna, referente à pauta acentual da tradução. A predominância de paroxítonas do português implica não apenas a presença de versos que terminam em átona como também o acréscimo de uma átona antes da cesura nos versos das estrofes da melodia principal. Por isso, em muitos casos os versos da tradução têm uma ou duas sílabas a mais do que os do original. Assim, em B, o primeiro verso da estrofe no original tem oito sílabas, contra 9 na tradução. Comparemos os dois versos no diagrama abaixo, em que cada par de linhas corresponde a um compasso da canção, nos dois idiomas: B1, o primeiro verso da segunda estrofe, vai do último tempo do primeiro compasso ao terceiro do segundo. A primeira linha indica os acentos do compasso: o primeiro tempo, o mais forte, é identificado pelo símbolo ///; o terceiro, menos marcado, é indicado por //; e o segundo e quarto, fracos, por $/$.

\begin{tabular}{|l|l|l|l|}
\hline /II & $/$ & $/ /$ & $/$ \\
\hline Dus-sel- & -dorf & & And \\
\hline -re- & -no & & Já \\
\hline ev'-ry night & at & five-o-nine & He'd \\
\hline en-ce-rra- & -d' o 'x- & -pe-di-en-te & Ca- \\
\hline
\end{tabular}

$\mathrm{Na}$ terceira coluna, que corresponde ao terceiro tempo do compasso quaternário, temos em inglês três sílabas (five-o-nine), mas na tradução temos quatro ("pe-di-en-te"), sendo a última átona, 
obrigando o cantor a articular mais uma sílaba; enquanto at five-o-nine corresponde a quatro notas, .....), “d' o 'x-pe-di-en-te" pede cinco: $\$$.... A A presença da quinta nota onde no original temos uma pausa implica uma pequena alteração no texto musical. A nota que parece mais natural inserir é a que completa a figura ascendente-descendente que precede o trecho, antecipando a última nota do compasso:

Figura 2
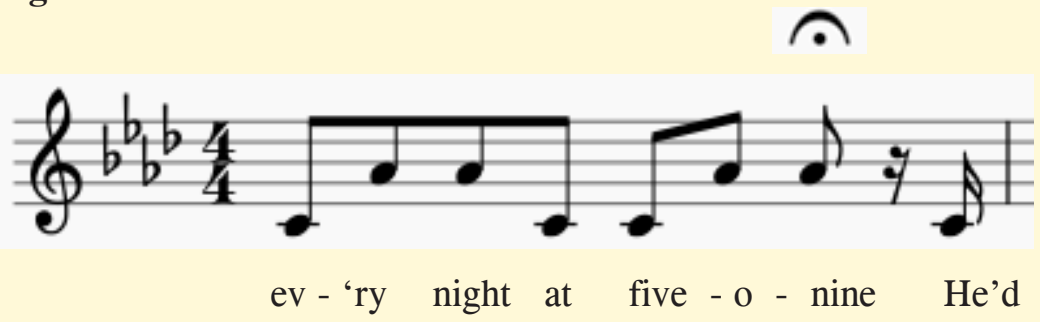

Fonte: Os autores.

Figura 3

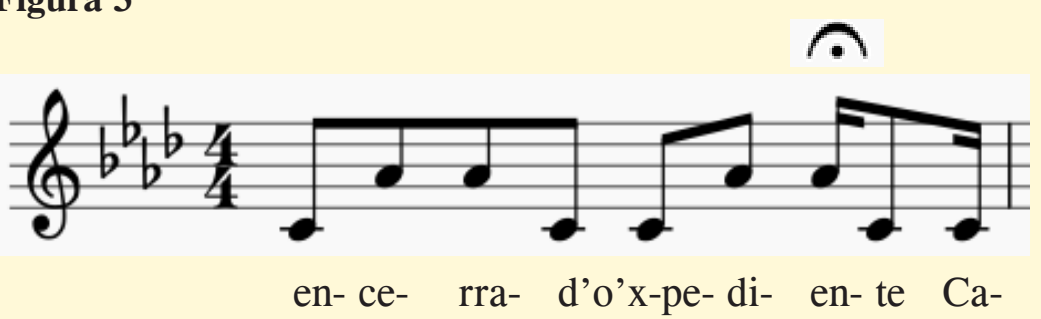

Fonte: Os autores.

Em termos de semântica, a comparação poderia apontar para a decisão de aproveitarmos a produtividade de manter o título, mas sem repeti-lo no primeiro verso, evitando tanto a longa palavra "Alemanha" quanto o choque vocálico entre o artigo "a" e este substantivo.

Assim, nossa primeira estrofe troca "antes da guerra" por "em paz ainda”. Muda-se a ação para 1933 a fim de facilitar as rimas, 
ainda que uma delas tenha acabado sendo incompleta, mas tradicionalmente considerada completa, derivada também ela de uma pequena alteração nos dados do poema, cuja ação agora transcorre diariamente um minuto mais tarde. A perda maior nestes versos é aquela vaga informação de que o protagonista "owned a store". Aqui, o índice de indeterminação cabe apenas àquele "e vai sereno", acréscimo que se, de um lado, quebra o esquema monorrímico inicial da letra original, abre a possibilidade de se rimar com "Reno" mais à frente.

$\mathrm{Na}$ estrofe B, a informação referente ao horário, antecipada para o segundo verso de A, é substituída pela ideia de que o expediente está encerrado, eliminando uma das (menores) ambiguidades, referente ao período do dia em que se passa a ação. $\mathrm{O}$ acréscimo de "em frente" localiza de maneira diferente a ação, e ficam faltando tanto a informação de que ele se "senta" quando aquele uso curioso da palavra shore, que já apontava para a dicotomia "mar/rio" no refrão.

Dada a manutenção geral dos efeitos rímicos, contudo, e a adesão mais ou menos rigorosa ao esquema métrico, talvez não se trate de perdas tão grandes, na medida em que a informação geral de localização temporal e geográfica é transmitida de maneira satisfatória.

No refrão, a troca do contínuo "I'm looking" pelo presente indicativo sintético do português brasileiro mal merece comentário. Dado o contexto o sentido aspectual mais frequente da construção em português (iterativo ou habitual), fica quase automaticamente descartado, em favor da leitura infectiva tradicional. A inserção do "é" enfático não apenas resolve um problema métrico como sublinha efeitos pragmáticos já contidos no texto original.

A estrofe seguinte foi a que mais versões diferentes recebeu durante o processo de tradução.

Podemos nos concentrar nas perdas. Ficamos sem o diminutivo "little girl", que amplia a pungência da história; não há a qualificação dos cabelos como "of gold", embora isso seja em alguma medida compensado pelo acréscimo de "da cor do céu” para se referir aos olhos. Mas os dois versos seguintes parecem dar conta 
de maneira razoavelmente satisfatória da semântica do original sem sacrificar demais os efeitos sonoros: uma sucessão de aliterações de oclusivas e, especialmente, a assonância do "e" nasalizado.

Em termos de estrutura métrica "cantável”, a manutenção do padrão original nos parece satisfatória, com a marcada exceção do quarto verso, onde há a subtração de uma sílaba ao original.

A estrofe final também corre riscos. De um lado, há a significativa perda da primeira pessoa plural, que completa no original esse passeio por perspectivas múltiplas. Perde-se também a referência ao outono e o dado "opressivo" da imagem dos personagens deitados "sob o céu". Por outro lado, conserva-se a marca do diminutivo em "menininha", ao mesmo tempo em que se perde a retomada do "ouro" dos cabelos, que no original agora se transformava num qualificativo dolorosamente irônico desta "golden girl".

Merece comentário o acréscimo do verso final. Apesar de não consideramos que aquele "me conforta" destoe significativamente do conteúdo e da noção geral do texto, ele aparece como novidade na tradução, com a explícita finalidade de gerar a suspeita de uma rima ausente (com "morta"). Trabalhamos a partir da análise proposta para os efeitos retóricos do poema, e nela essa "suspensão" da rima tem efeito importante, justificando a aparente radicalidade de "rimarmos" com uma palavra ausente.

Cotejemos as duas letras, assinalando coincidências e defasagens entre acento lexical e musical. Dentro de cada um deles, as duas primeiras linhas (levemente sombreadas) apresentam os acentos lexicais na de cima e o texto na debaixo; nas duas seguintes (não sombreadas), o mesmo para o texto traduzido. Os números na coluna da esquerda referem-se aos compassos. Foram omitidos os últimos compassos da canção, puramente instrumentais. 


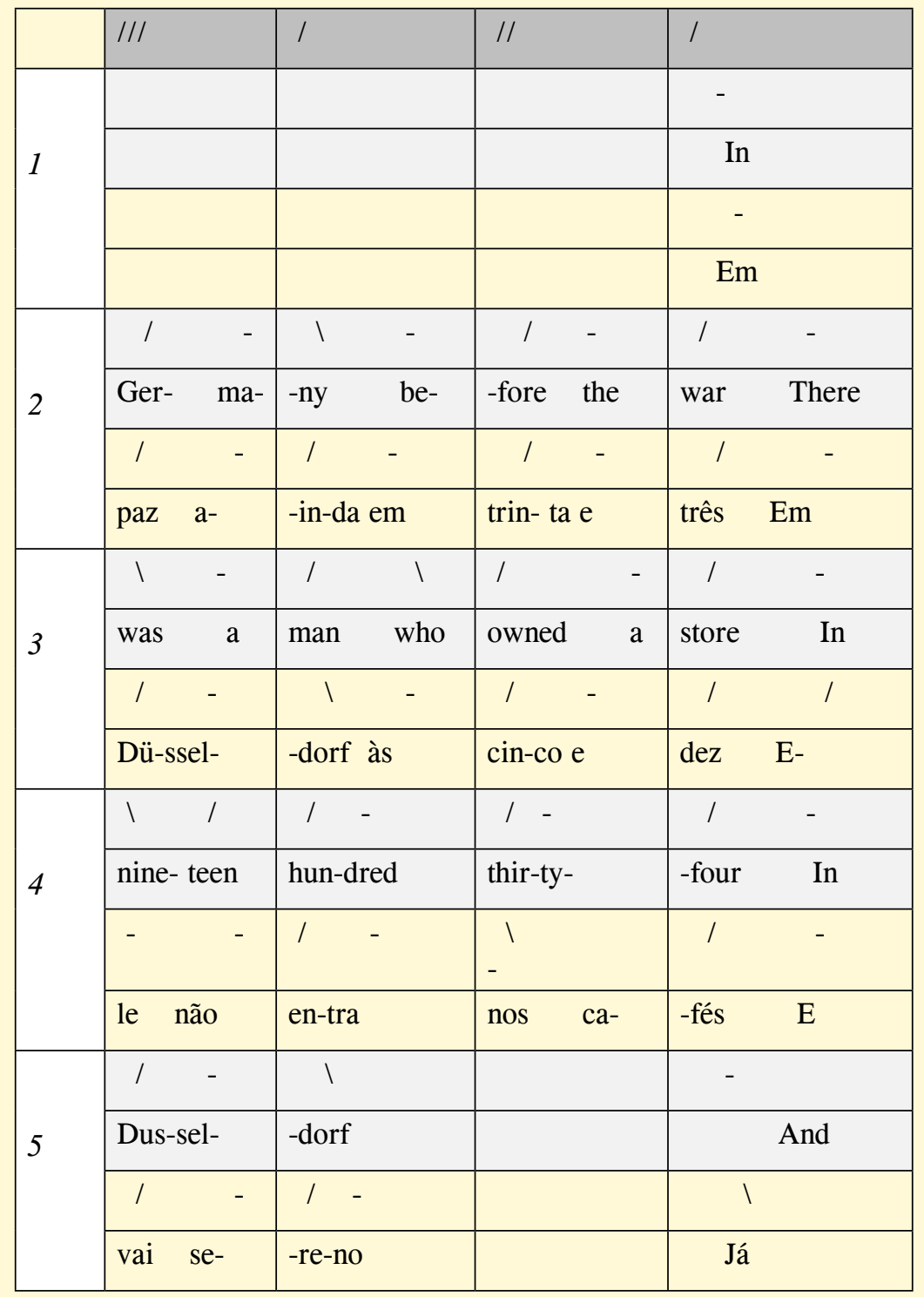




\begin{tabular}{|c|c|c|c|c|}
\hline \multirow{4}{*}{6} & $1 \quad-$ & $1 \quad-$ & $1 \quad-$ & $1 \quad-$ \\
\hline & ev'-ry & night at & five-o' & -nine $\quad H e^{\prime} d$ \\
\hline & 1 & 1 & $1-$ & $1 \quad-\quad-$ \\
\hline & en-ce- & -rra-do o ' $\mathrm{x}$ - & -pe-di- & -en-te $\mathrm{Ca}$ - \\
\hline \multirow{4}{*}{7} & $1 \quad-$ & $\begin{array}{ll}1 & 1\end{array}$ & $1-$ & $1 \quad-$ \\
\hline & cross the & park down & to the & Rhine And \\
\hline & I - & $1 \quad-$ & $1 \quad-$ & $1 \quad-$ \\
\hline & -mi-nha a- & -té o & par-que em & fren-te $E$ \\
\hline \multirow{4}{*}{8} & $1 \quad-$ & $1-$ & 1 & \\
\hline & sit there & by the & shore & \\
\hline & I & 1 & 1 & \\
\hline & o-lha & pa-ra o & Re-no & \\
\hline \multirow{4}{*}{9} & & & & - \\
\hline & & & & I'm \\
\hline & & & & - \\
\hline & & & & $\mathrm{Eu}$ \\
\hline \multirow{4}{*}{10} & $1 \quad-$ & $1-$ & $1-$ & $-\quad-$ \\
\hline & look-ing & at the & riv-er & But I'm \\
\hline & I & - & $1-$ & $-\quad-$ \\
\hline & o-lho & pa-ra o & ri-o & Mas eu \\
\hline \multirow{4}{*}{11} & $1 \quad-$ & $1-$ & 1 & - \\
\hline & think-ing & of the & sea & I'm \\
\hline & I & 1 & 1 & - \\
\hline & pen-so & é no & mar & $\mathrm{eu}$ \\
\hline
\end{tabular}




\begin{tabular}{|c|c|l|l|l|}
\hline \multirow{4}{*}{12} & $/$ & $1-$ & $/$ & \\
\cline { 2 - 5 } & think-ing & of the & sea & \\
\hline & $/$ & $1-$ & $/$ & \\
\hline & pen-so & é no & mar & \\
\hline
\end{tabular}

\begin{tabular}{|c|c|c|c|c|}
\hline \multirow{4}{*}{13} & & & & - \\
\hline & & & & I'm \\
\hline & & & & - \\
\hline & & & & $\mathrm{Eu}$ \\
\hline \multirow{4}{*}{1} & $1 \quad-$ & $1-$ & $1-$ & $-\quad-$ \\
\hline & look-ing & at the & river & But I'm \\
\hline & I & 1 & $1-$ & - \\
\hline & o-lho & pa-ra o & ri-o & Mas eu \\
\hline \multirow{4}{*}{15} & $1 \quad-$ & $1-$ & I & \\
\hline & think-ing & of the & sea & \\
\hline & 1- & $1-$ & I & \\
\hline & pen-so & é no & mar & \\
\hline \multicolumn{5}{|l|}{16} \\
\hline & & & & \\
\hline & & & & \\
\hline
\end{tabular}




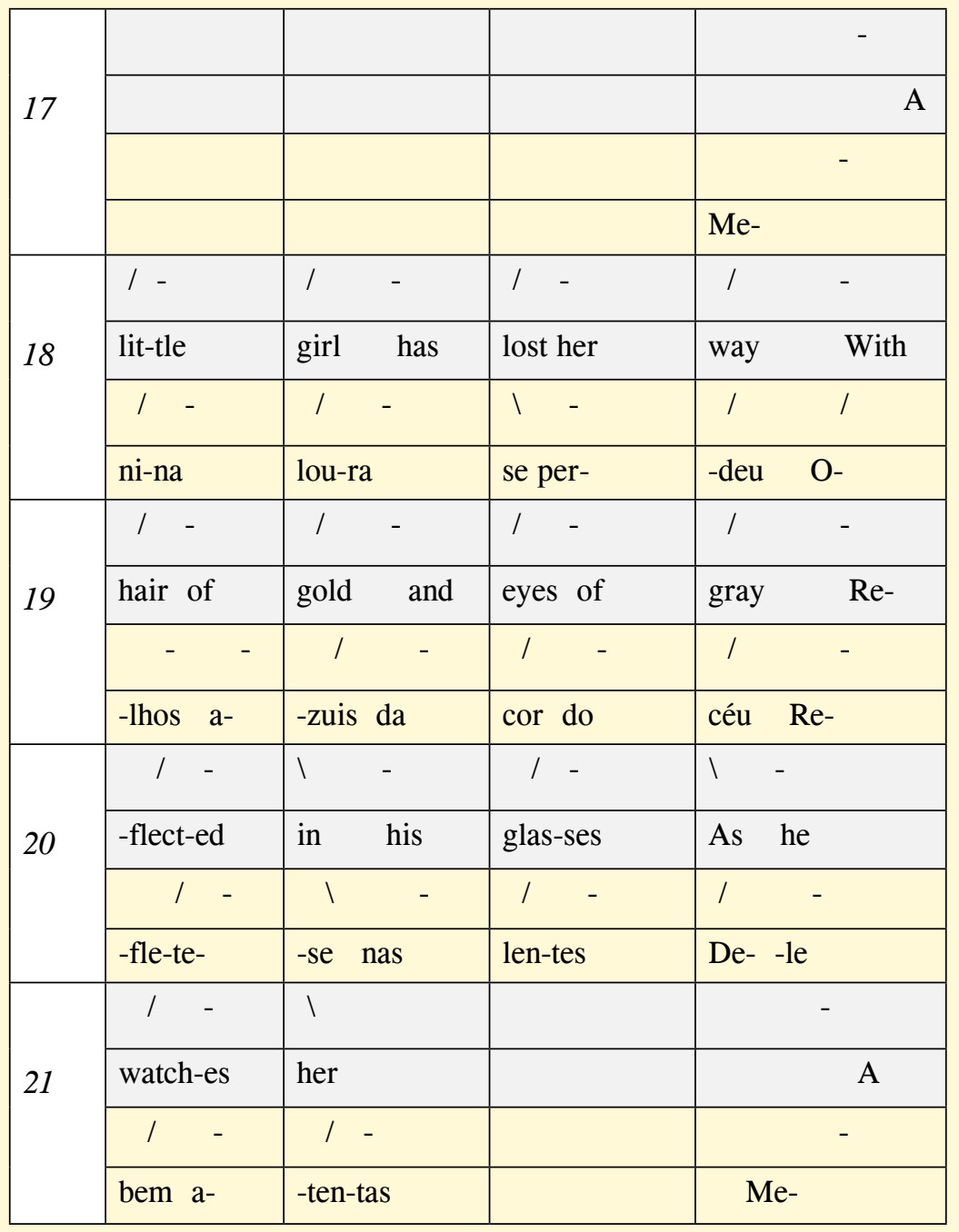




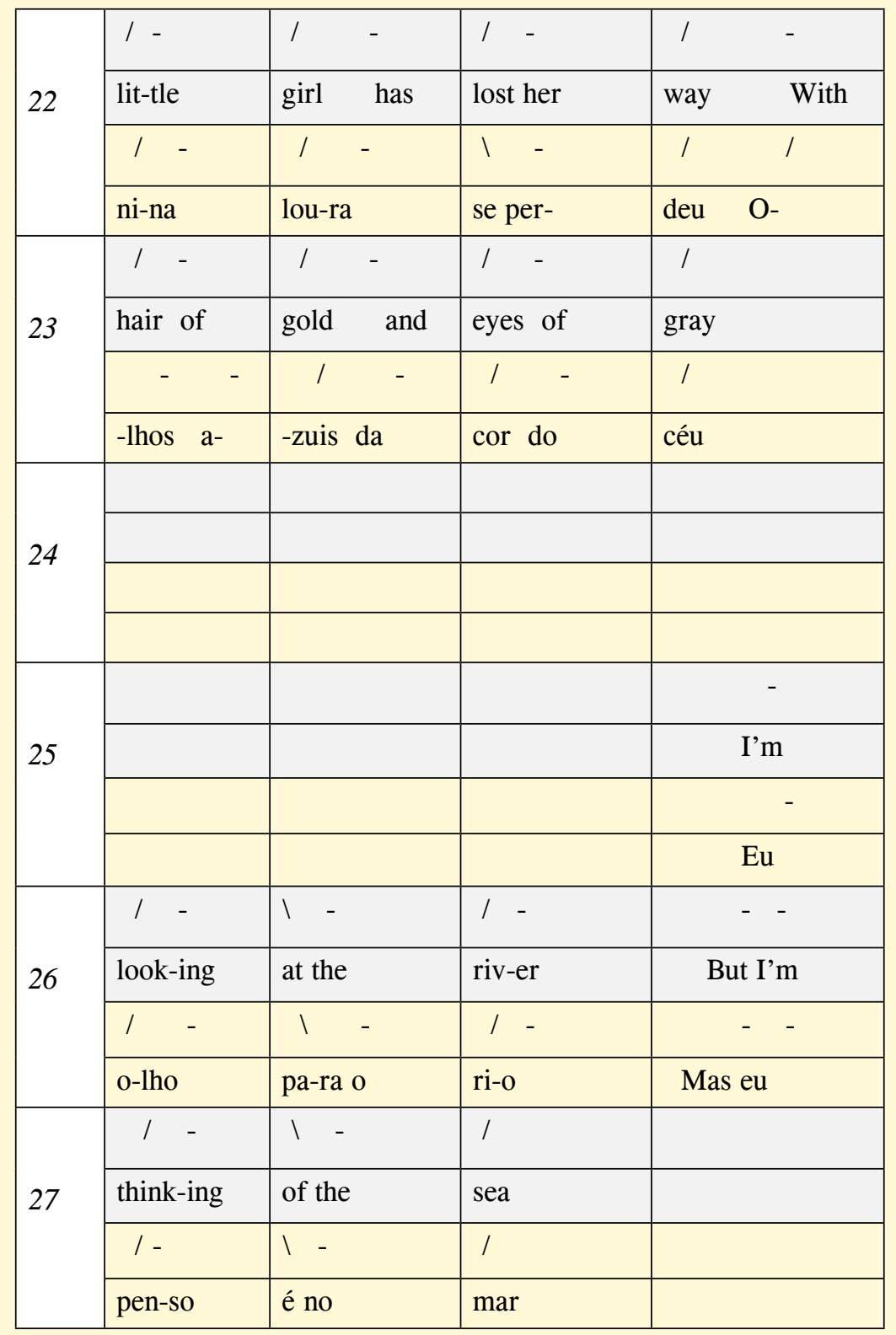




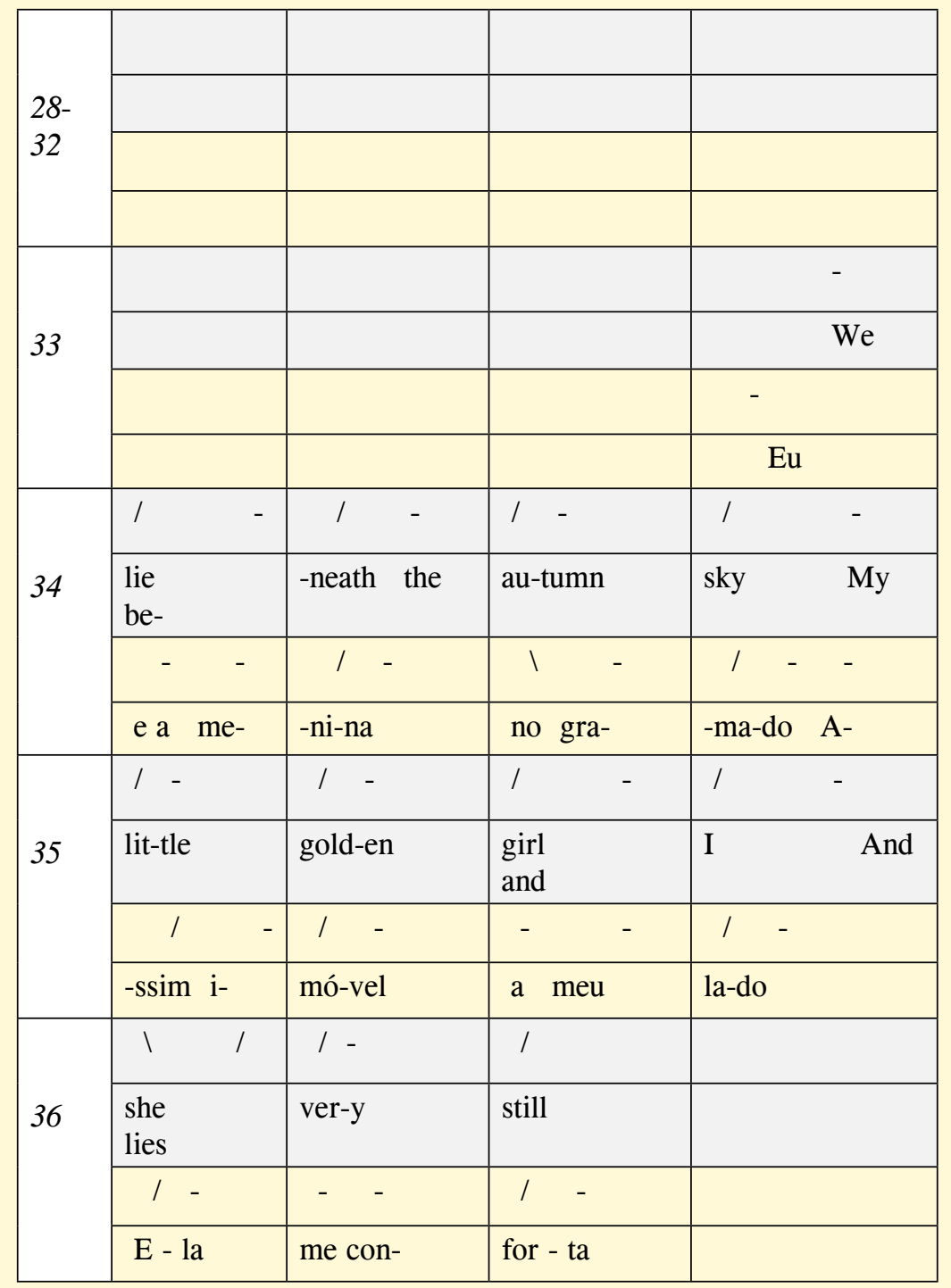

Esta análise pode parecer excessivamente minuciosa. Mas julgamos necessário revelar a que ponto pode ir a sofisticação do ori- 
ginal, para então podermos ter condições de pensar as estratégias de tradução, e seu grau de sucesso.

A canção de Newman nos parece uma ocasião privilegiada para se sondar o potencial de procedimentos, sutis, que se somam para gerar um efeito a princípio subjetivo. Resta a possibilidade de que a execução da versão, feita a partir do que nos parece ser o exame lúcido dos mecanismos de funcionamento desses procedimentos formais de concatenação de palavra e som, passe, ou não, na prova dos nove dessa mesma recepção "subjetiva".

\section{Discografia}

Newman, Randy. Little Criminals. Las Vegas: Reprise, 1977.

Newman, Randy. The Randy Newman Songbook Vol. 1. California: Nonesuch, 2003.

Recebido em: 22/08/2020

Aceito em: 05/10/2020

Publicado em janeiro de 2021

Caetano Galindo. E-mail: cwgalindo@gmail.com. ORCID: https://orcid. org/0000-0002-0437-1664.

Paulo Henriques Britto. E-mail: phbritto@hotmail.com. ORCID: https://orcid. org/0000-0002-8979-2424. 